\title{
Analisis Tingkat Kesehatan Bank Dengan Menggunakan Metode Rgec Pada PT. Bank Tabungan Negara, Tbk. Periode 2015-2017
}

\author{
Fina Priskila Kawengian \\ Frendy A. O. Pelleng \\ Wilfried S. Manoppo \\ Jurusan Ilmu Administrasi, Program Studi Administrasi Bisnis \\ Fakultas Ilmu Sosial dan Politik, Universitas Sam Ratulangi \\ finapriskila10@gmail.com
}

\begin{abstract}
This study aimed to analyze the health of a bank, at PT. Bank Tabungan Negara, Tbk. by using the Rgec method. The Rgec method consists of several components, namely Risk Profile, Good Corporate Governance, Earnings, Capital. of these components also have indicators. which will later rank a bank which is ranked in what category, based on calculations through the company's financial statement data. This research uses quantitative descriptive research. The data source used is secondary data with documentation data collection techniques. Based on the results of data analysis, it was concluded that during the 2015-2017 period, (1) Bank BTN risk profile was in a healthy condition with NPL of 1,60\%, 1,40\% and 1,30\% respectively, and LDR of 109,54\%, 103,63\%, and 104,19\%. (2) GCG for the period 2015-2017 is 2 with healthy criteria. (3) Earnings in the 2015-2017 period are in a healthy condition with ROA of 1,47\%, 1,55\%, and 1,47\%, NIM of 3,96\%, 3,81\%, and $3,57 \%$, BOPO was 78,67\%, 77,96\% and 77,12\%. (4) Capital is in a very healthy condition with a CAR value of 16,96\%, 20,33\% and 18,86\%. (5) Rgec as a whole is in Composite Rating 1 which is very healthy with a value of $85,71 \%$.
\end{abstract}

Keywords: the health of bank, methods Rgec.

\section{Pendahuluan}

Indonesia memiliki cukup banyak lembaga keuangan, dan perbankan adalah salah satu lembaga keuangan yang memiliki peran strategis dalam perekonomian di Indonesia. secara lebih luas lagi bahwa bank merupakan perusahaan yang bergerak dalam bidang keuangan, artinya aktivitas perbankan selalu berkaitan dalam bidang keuangan. Sehingga berbicara mengenai bank tidak terlepas dari masalah keuangan (Kasmir:2014). Sangat penting bank dinilai tingkat kesehatannya, apakah bank tersebut dalam kondisi yang sehat, cukup sehat, kurang sehat, ataupun tidak sehat, hal ini berguna bagi pihakpihak yang berkepentingan dalam mengambil keputusan. Selain itu Otoritas Jasa Keuangan mewajibkan bank paling sedikit setiap semester untuk dinilai tingkat kesehatannya. Dalam peraturan tersebut mewajibkan semua bank umum agar melakukan penilaian sendiri (self assesment) Tingkat Kesehatan Bank menggunakan pendekatan risiko (Riskbassed Bank Rating/RBBR) baik secara 
individual atau secara konsolidasi, yang perhitungannya berpedoman pada Surat Edaran Bank Indonesia (SEBI) No 13/24/DPNP tanggal 25 Oktober 2011 yang penilaiannya meliputi faktor-faktor Risk Profile, Good Corporate Governance, Earning, Capital (RGEC). Dengan mengalisis laporan keuangan bank tersebut. Laporan keuangan merupakan hasil akhir dari suatu proses akuntansi. Metode RGEC merupakan tata cara penilaian bank yang menggantikan tata cara penilaian bank sebelumnya yaitu CAMEL (www.bi.go.id).

PT. Bank Tabungan, Tbk. (Bank) adalaha Badan Usaha Milik Negara (BUMN) yang bergerak dibidang perbankan. Tahun 2017 Bank BTN menerima penghargaan emas dalam kategori "Corporate Governance and Investor Reletionship" dari The Asset Publishing and Research Limited, Hong Kong. Namun, peringkat itu belum tentu sama untuk peringkat pada bidang keuangan. Dengan menggunakan pendekatan RGEC sebagai metode untuk mengetahui sisi pada bidang keuangan Bank BTN, dan diharapkan dapat membantu peneliti untuk menilai tingkat kesehatan (www.btn.co.id) Dengan latar belakang yang demikian dan juga menyangkut Pentingnya tingkat kesehatan bank, guna mempertahankan bahkan meningkatkan kepercayaan masyarakat terhadap bank, membuat saya tertarik untuk melakukan penelitian tingkat kesehatan bank dengan judul "Analisis Tingkat Kesehatan Bank Menggunakan Metode Rgec Pada Pt. Bank Central Asia, Tbk Periode Tahun 2015-2017" . Dengan rumusan masalah sebagai berikut: Bagaimana tingkat kesehatan PT. Bank Tabungan Negara, Tbk. pada periode 20152017 jika diukur dengan menggunakan pendekatan metode RGEC?

\section{Metode Penelitian}

PT. Bank Tabungan Negara,Tbk. diputuskan untuk dilakukannya penelitian ini pada periode 2015-2017 melalui situs www.btn.co.id Waktu penelitian ini dilaksanakan mulai Januari 2019 sampai Maret 2019. Dalam penelitian ini, jenis penelitian yang digunakan adalah jenis penelitian deskriptif kuantitatif.Fokus penelitian ini adalah penilaian terhadap faktor RGEC pada PT. Bank Tabungan Negara,Tbk. dan menentukan tingkat kesehatannya. Analisis data dalam penelitian ini adalah berdasarkan pokokpokok pengaturan tingkat kesehatan bank diuraikan pada PBI No. 13/01/PBI/2011 dan SE 13/24/DPNP tanggal 25 Oktober 2011 yang menjadi indikator adalah:

$$
\text { Risk Profil (Profil Resiko) }
$$

a. Risiko kredit

$$
\begin{array}{r}
\text { NPL }=\frac{\text { Kredit Bermasalah }}{\text { Total Kredit }} \times 100 \% \\
\text { b. } \quad \text { Resiko Likuiditas } \\
L D R=\frac{\text { Total Kredit }}{\text { Dana Pihak Tiga }} \times 100 \%
\end{array}
$$


(2) Good Corporate Governance

Good Corporate Governance dalam pengukurannya menggunakan metode Self Assesment karena berdasarkan SE BI No. 15/15/DPNP Tahun 2013 mewajibkan Self Assesment dalam mengukur GCG.

Earnings (Rentabilitas)

Earnings adalah salah satu penilaian kesehatan bank dari sisi rentabilitas. Indikator penilaian rentabilitas:

(a) ROA (Return On Assets)

$$
R O A=\frac{\text { Laba Sebelum Pajak }}{\text { Rata }- \text { rata Total Aset }} \times 100 \%
$$

(b) NIM (Net Interest Margin)

$$
\mathrm{NIM}=\frac{\text { Pendapatan Bunga Bersih }}{\text { Rata }- \text { rata Aktiva Produktif }} \times 100 \%
$$

(c) BOPO (Beban Operasional Terhadap Pendapatan Operasional

$$
\text { BOPO }=\frac{\text { Biaya Operasional }}{\text { Pendapatan Operasional }} \times 100 \%
$$

Komponen laba actual terhadap proyeksi anggaran dan kemampuan komponen laba dalam meningkatkan permodalan.

\section{(4) Capital}

Rasio kecukupan modal atau Capital Adequacy Ratio (CAR) adalah rasio kecukupan modal yang berfungsi menampung risiko kerugian yang kemungkinan dihadapi oleh bank.

$$
C A R=\frac{\text { Modal Bank }}{\text { Total ATMR }} x 100 \%
$$

Subjek dalam penelitian ini adalah PT. Bank Tabungan Negara, Tbk. Objek dalam penelitian ini adalah laporan keuangan dari PT. Bank Tabungan Negara, Tbk. periode 2015-2017.

\section{Hasil Dan Pembahasan}

(1) Risk Profil (Profil Resiko)

a). Non Performing Loan

Tabel 1 Kesehatan Bank Tabungan Negara berdasarkan rasio NPL

Tahun Nilai Peringkat Predikat

\begin{tabular}{llll}
\hline 2015 & $1,60 \%$ & 1 & Sangat sehat \\
\hline 2016 & $1,40 \%$ & 1 & Sangat sehat \\
\hline 2017 & $1,30 \%$ & 1 & Sangat sehat
\end{tabular}

Sumber : Data sekunder yang diolah peneliti, 2019.

Nilai rasio NPL yang semakin kecil menunjukkan bahwa bank semakin baik dalam menyeleksi calon peminjam sehingga jumlah kredit yang tergolong kurang lancar, diragukan dan macet pun berkurang. Nilai NPL Bank BTN selama tahun 2015-2017 adalah 1,49\%, 1,30\%, $1,19 \%$ nilai tersebut menunjukan bahwa kualitas kredit Bank BTN berada pada kondisi yang sangat sehat. Dan hal ini menunjukan bahwa upaya manajemen dalam mengelola tingka kolektabilitas dan menjaga kualitas kredit di setiap tahunnya seakin membaik dan memberikan hasil yang positif, sehingga mampu menghasilkan pertumbuhan kredit yang cukup berkualitas. 


\section{b). Loan to Deposito Ratio}

Tabel 2 Kesehatan Bank Tabungan Negara berdasarkan rasio LDR

Tahun Nilai Peringkat Predikat

$2015 \quad 109,54 \% \quad 4 \quad$ Kurang sehat

$2016 \quad 103,63 \% \quad 4 \quad$ Kurang sehat

$2017 \quad 104,19 \% \quad 4 \quad$ Kurang sehat

Sumber : Data sekunder yang diolah peneliti, 2019.

Secara keseluruhan sebaiknya Bank BTN perlu mengetatkan jumlah kredit yang disalurkan dan tetap menjaga prinsip kehaihatian di tahun mendatang, dilihat dari nilai LDR tahun 2015-2017 adalah109,54\%, 103,63\%, dan 104,19\%. Apabila memiliki nilai LDR yang terlalu tinggi akan menunjukan bahwa bank terlalu agresif dalam menyalurkan kredit sehingga dapat meningkatkan kemungkinan resiko yang di hadapi. Seharusnya bank perlu menjaga tingkat LDR pada nilai yang ideal yang telah ditetapkan oleh Bank Indonesia yaitu sebesar 50\%-75\%, juga lebih memperhatikan seluruh kewajiban bank terlebih khusus kewajiban jangka pendek dan berusaha untuk menyeimbangkan antara pemberian kredit dengan banyaknya dana yang diterima dari pihak ketiga agar likuiditas bank dapat terjaga.

(2) Good Corporate Governance (GCG) Tabel 3 Kesehatan Bank Tabungan Negara berdasarkan Self assessment
Tahun Nilai Peringkat Predika

\begin{tabular}{llll}
\hline 2015 & 2 & 2 & Sehat \\
\hline 2016 & 2 & 2 & Sehat \\
\hline 2017 & 2 & 2 & Sehat
\end{tabular}

Sumber : Data sekunder yang diolah peneliti, 2019.

Berdasarkan table 3 diatas, dapat disimpulkan bahwa rata-rata nilai GCG periode 2015-2017 adalah 2. Bank BTN memperoleh nilai GCG yang cukup tinggi dan menerima penghargaan dengan peringkat penilaian perusahaan "Sangat terpercaya". Dewan komisaris meyakini struktur tata kelola perusahaan yang telah dikembangkan di perseroan sudah sangat baik dan mampu mendukung pertumbuhan perusahaan yang profitable dan berkelanjutan. Hal ini berarti bahwa manajemen perusahaan dalam mengelola Governance sudah baik karena GCG periode 2015-2017 berada dikategori sehat.

(3) Earnings (Rentabilitas)

a). Return On Asset

Tabel 4 Kesehatan Bank Tabungan Negara berdasarkan rasio $\mathrm{ROA}$

\begin{tabular}{lccl}
\hline Tahun & Nilai & Peringkat & Predikat \\
\hline 2015 & $1,47 \%$ & 2 & Sehat \\
\hline 2016 & $1,55 \%$ & 2 & Sehat \\
\hline 2017 & $1,47 \%$ & 2 & Sehat
\end{tabular}

Sumber : Data sekunder yang diolah peneliti, 2019. 
Terlihat bahwa ROA Bank BTN pada periode 2015-2015 adalah 1,47\%, 1,55\%, dan $1,47 \%$. Nilai ini menyatakan bahwa ROA Bank BTN mengalami fluktuasi namun tidak memberikan dampak yang negatif karena berada pada kategori sehat.

b). Net Interest Margin

Tabel 5 Kesehatan Bank Tabungan Negara berdasarkan rasio NIM

Tahun Nilai Peringkat Predikat

$2015 \quad 3,96 \% \quad 1 \quad$ Sangat sehat

$2016 \quad 3,81 \% \quad 1 \quad$ Sangat sehat

$2017 \quad 3,57 \% \quad 1 \quad$ Sangat sehat

Sumber : Data sekunder yang diolah peneliti, 2019.

Nilai margin bunga bersih bank BTN periode 2015-2017 sebesar 3,96\%, 3,81\%, dan $3,57 \%$, nilai rasio ini terus menurun, hal ini disebabkan oleh kenaikan suku bunga sehingga menyebabkan tingginya biaya bunga yang di tanggung oleh bank. Secara keseeluruhan nilai tersebut menunjukan kemampuan bank dalam memperoleh pendapatan bunga bersih selama tiga tahun sudah sangat baik dan masuk dalam kategori sangat sehat.

c). Biaya Operasional terhadap Pendapatan Operasional

Tabel 6 Kesehatan Bank Tabungan Negara berdasarkan rasio BOPO
Tahun Nilai Peringkat Predikat

$2015 \quad 78,67 \% \quad 1 \quad$ Sangat sehat

$2016 \quad 77,96 \% \quad 1 \quad$ Sangat sehat

$2017 \quad 77,12 \% \quad 1 \quad$ Sangat sehat

Sumber : Data sekunder yang diolah peneliti, 2019.

Nilai rasio BOPO Bank BTN periode 20152017 berturut-turut mengalami penurunan, yaitu $78,67 \%, 77,96 \%$, dan $77,12 \%$. Hal ini di sebabkan beban operasional yang menurun, menunjukan kemampuan bank dalam manajemen beban operasional dan pendapatan operasional selama tiga tahun tersebut sangat baik dan masuk dalam kategori sangat sehat.

\section{(4) Capital (Permodalan)}

Tabel 7 Kesehatan Bank Tabungan Negara berdasarkan rasio CAR

Tahun Nilai Peringkat Predikat

$2015 \quad 16,96 \% \quad 1 \quad$ Sangat sehat

$2016 \quad 20,33 \% \quad 1 \quad$ Sangat sehat

$2017 \quad 18,86 \% \quad 1 \quad$ Sangat sehat

Sumber : Data sekunder yang diolah peneliti, 2019.

Tingkat kesehatan bank dilihat dari Capital dengan menghitung Capital Adeqacy Ratio pada Bank BTN periode 2015-2017 memiliki nilai $16,96 \%, 20,33 \%$, dan $18,86 \%$ dengan kategori sangat sehat. CAR yang besar menunjukan bahwa bank dapat menyangga kerugian operasional bila 
terjadi dan dapat mendukung pemberian kredit yang besar. CAR yang besar juga dapat meningkatkan kepercayaan dari masyarakat untuk menyalurkan dananya ke Bank BTN. Nilai CAR yang dimiliki Bank BTN selama tiga periode tersebut berada diatas standar yang telah di tetapkan sehingga bank dinilai telah mampu memenuhi kewajiban penyedia modal minimum.

(5) Aspek RGEC

Tabel 8 Tingkat kesehatan Bank menurut RGEC

Nilai Kredit RGEC Peringkat Predikat

$81 \%-100 \% \quad 1 \quad$ Sangat sehat

\begin{tabular}{lll}
\hline $66 \%-81 \%$ & 2 & Sehat
\end{tabular}

\begin{tabular}{lll}
\hline $51 \%-66 \%$ & 3 & Kurang sehat
\end{tabular}

$0 \%-51 \% \quad 4 \quad$ Tidak sehat

Sumber : Data sekunder yang diolah peneliti, 2019.

Penilaian tingkat kesehatan Bank BTN dengan menggunakan metode RGEC selama periode 2105-2017 berada pada peringkat komposit 1 (PK-1) dengan kriteria sangat sehat. Dengan rincian bahwa pada tahun 2015-2017 peringkat komposit Bank BTN adalah berturut-turut 85,71\%, dengan kriteria sangat sehat.

\section{Kesimpulan}

Hasil penilaian Profil Resiko (Risk profil) Bank BTN dengan nilai NPL Bank BTN selama tahun 2015-2017 berturut- turut adalah 1,49\%,1,30\%,1,19\% berada dalam kondisi sangat sehat. Nilai rasio LDR Bank BTN selama tahun 2015-2017 berturut-turut adalah 109,54\%, $103,63 \%, 104,19 \%$ berada dalam kondisi kurang sehat.

Hasil penilaian Good Corpoorate Governance (GCG) Bank BTN pada tahun 2015-2017 diperoleh nilai GCG sebesar 2, 2 , dan 2 yang artinya pelaksanaan prinsipprinsip GCG pada tahun tersebut telah terlaksana dengan baik . karena nilai tersebut dalam kategori sehat.

Hasil Penilaian Rentabilitas (Earning) Bank BTN dengan menggunakan tiga rasio yaitu ROA, NIM dan BOPO selama tahun 2015-2017 berada dalam kondisi sangat sehat. Hal ini terbukti dengan nilai ROA Bank BTN tahun 20152017 berturut-turut adalah 1,47\%, $1,55 \%, 1,47 \%$ berada dalam kondisi yang sehat. Nilai NIM tahun 2015-2017 berturutturut adalah 3,96\%, 3,81\%,3,57\% berada dalam kondisi sangat sehat. Nilai BOPO tahun2015-2017 berturut-turut adalah $78,67 \%, 77,96 \%, 77,12 \%$ berada dalam kondisi sangat sehat.

Hasil penilaian Permodalan (Capital) Bank BTN selama tahun 20152017 berada dalam kondisi sangat sehat. Hal ini dibuktikan dengan nilai CAR selama tiga tahun berturut-turut adalah $16,96 \%, 20,33 \%, 18,86 \%$ dengan kriteria sangat sehat. 
Hasil Penilaian tingkat kesehatan Bank BTN dilihat dari aspek RGEC selama tahun 2015-2017 menempati Peringkat komposit 1 (PK-1). Apabila terdapat kelemahan maka secara umum kelemahan tersebut tidak signifikan.

\section{Saran}

Dari hasil kesimpulan dalam penelitian ini, maka akan diberikan beberapa saran-saran yaitu sebagai berikut :

Sebaiknya pihak manajemen bank lebih selektif dan hati-hati dalam pemberian kredit terhadap nasabah dan mengikuti peraturan perkreditan yang telah ditetapkan oleh Bank Indonesia untuk menghindari terjadinya kredit macet. Untuk aspek likuiditas sebaiknya Bank BTN yang memiliki rasio LDR yang melebihi batas maksimal dari ketentuan yang telah ditetapkan oleh Bank Indonesia untuk lebih memperhatikan seluruh kewajiban bank terlebih khusus kewajiban jangka pendek dan berusaha untuk menyeimbangkan antara pemberi kredit dengan banyaknya dana yang diterima dari pihak ketiga agar likuiditas bank dapat terjaga.

Bank BTN harus tetap mempertahankan peringkat yang sudah di capai atau bahkan harus meningkatkan nilai yang sudah d capai. Agar juga perusahaan terus mendapat tingkat kepercayaan yang tinggi dari nasabah, bahkan semua pihak yang berkepentingan dengan Bank BTN.
Kemampuan Bank BTN dalam memperoleh laba dengan mengandalkan asetnya, bank BTN harus menekan dan mengelola biaya operasional dengan sebaik mungkin, agar terus mendapatkan nilai pendapatan operasional yang lebih baik.

Nilai CAR yang besar menunjukan bahwa bank dapat menyangga kerugian operasional bila terjadi dan dapat mendukung pemberian kredit yang besar, hal ini harus tetap dipertahankan Bank BTN , supaya terus mendapat kepercayaan dari masyarakat untuk menyalurkan dana ke Bank BTN.

Dengan hasil yang sangat sehat telah dicapai oleh Bank BTN, harus terus mengalami peningkatan, Supaya masyarakat tetap mempercayai Bank BTN.

\section{Daftar Pustaka}

Dr. Kasmir, SE., MM. 2014. Bank Dan Lembaga Keuangan. Edisi Revisi 2014. Jakarta: Rajawali Pers.

Gandawari Y. 2017. Analisis Tingkat Kesehatan BankMenggunakan Metode RGEC Pada PT. Bank SulutGo Periode 2014-2016.Jurnal Administrasi Bisnis 5, (3).http://ejournal.unsrat.ac.id

Ikatan Bankir Indonesia. 2016. Manajemen Kesehatan Bank Berbasis Resiko. Jakarta: PT. Gramedia Pustaka Utama.

Surat Edaran Bank Indonesia No. 15/15/DPNP tanggal 29 April 2013.Tentang Pelaksanaan Good Corporate Governance bagi Bank 
Umum. Jakarta: Bank Indonesia.

https://www.bi.go.id

Surat Edaran Bank Indonesia No. 13/24/DPNP tanggal 25 Oktober 2011.Tentang Matriks Perhitungan Analisis Komponen Faktor Analisis RGEC untuk Bank Umum. Jakarta: Bank Indonesia. https://www.bi.go.id 